\title{
Smoking in adolescence and young adulthood and mortality in later life: prospective observational study
}

\author{
P McCarron, G Davey Smith, M Okasha, J McEwen
}

As experimentation with smoking occurs overwhelmingly in adolescence, a major objective of government strategy is to reduce smoking among young people. ${ }^{1}$ However, most studies of the association between mortality and smoking have relied on data for people whose smoking behaviour was recorded in middle age; teenagers and young adults may not see the relevance of messages derived from these studies or may feel that they are to some extent immune from the health damaging effects of smoking. Few studies have examined the association between mortality and smoking behaviour in early life. In US college students who reported their smoking behaviour between 1916 and 1950 risk of cancer and cardiovascular disease (CVD) was increased among individuals who smoked in young adulthood ${ }^{2}$ while in a large prospective study of women's health participants who started smoking before the age of 15 years had the highest risks for total mortality, CVD mortality and deaths from injury. ${ }^{3}$ The first of these studies did not fully analyse the role of potential confounders while the second relied on recall of past smoking experience. To investigate this issue further we examined the association between smoking in young adulthood and risk of mortality in a cohort of male students from Glasgow Univer-

$\begin{array}{ll}\text { P McCarron } & \text { sity. }\end{array}$

M Okasha

Department of Public Health, University of Glasgow

$\mathrm{J}$ McEwen

Correspondence to:

Dr McCarron

(mccarrop@mail.nih.gov)

Accepted for publication

4 December 2000
NHS Central Register. Full details are reported elsewhere. ${ }^{4}$

Cox proportional hazards models were used to estimate the effect of smoking, categorised as none, mild (1-10), moderate (11-20) and heavy ( $>20$ cigarettes per day) on all cause mortality and on mortality from: CVD; coronary heart disease (CHD); stroke; smoking related cancers (lip, tongue, mouth and pharynx, oesophagus, pancreas, respiratory tract, and urinary tract); cancers unrelated to smoking; respiratory disease; "other" causes (all causes except CVD, smoking related cancers, respiratory diseases and alcohol related disease); and alcohol related disease (all and only those unrelated to smoking). Deaths up to 31 December 1998 were included in the analyses. Analyses were adjusted for the following potential confounders: systolic blood pressure (except cancer and respiratory disease), body mass index, father's social class and year of birth quintile, with additional adjustment for alcohol consumption in analyses of alcohol related deaths.

\section{Results}

A total of 11755 male students participated in the original examinations. We have traced 9887 $(84.1 \%)$ of these. After excluding those aged over 30 years, those who had left the UK at an undetermined date and those with missing data on smoking behaviour there were 8354 men available for inclusion in the analyses. Median follow up time was 41.3 years.

The mean age of the students at the time of examination was 20.5 years (range 16-29 years). Age adjusted results were similar for the full cohort and the 8354 men with data available on potential confounders. As there

Table 1 Hazard ratios for association between smoking and mortality from all causes, CVD, CHD, smoking related cancers and alcohol related disease in men

\begin{tabular}{|c|c|c|c|c|c|}
\hline \multicolumn{2}{|l|}{ Cause of death (number) } & \multicolumn{3}{|c|}{ Hazard ratios $(95 \%$ CI) } & \multirow[t]{2}{*}{$\begin{array}{l}\text { p for trend across } \\
\text { categories }\end{array}$} \\
\hline Smoking category $(n)$ & None (5728) & $1-10(2150)$ & $11-20(692)$ & $>20(38)$ & \\
\hline$\star \star A l l$ causes $(n=861)$ & 1 & $1.42(1.21$ to 1.65$)$ & $2.08(1.71$ to 2.53$)$ & $3.39(1.81$ to 6.36$)$ & $<0.001$ \\
\hline${ }^{\star \star} \mathrm{CVD} \dagger(\mathrm{n}=339)$ & 1 & $1.40(1.09$ to 1.78$)$ & $2.29(1.68$ to 3.00$)$ & $4.18(1.68$ to 10.03$)$ & $<0.001$ \\
\hline${ }^{\star} \mathrm{CHD} \neq(\mathrm{n}=243)$ & 1 & $1.44(1.07$ to 1.94$)$ & $2.67(1.89$ to 3.77$)$ & $3.73(1.18$ to 11.80$)$ & $<0.001$ \\
\hline${ }^{\star \star}$ Stroke $\(\mathrm{n}=66)$ & 1 & $1.12(0.65$ to 1.93$)$ & $1.00(0.46$ to 2.18$)$ & $2.96(0.40$ to 21.82$)$ & 0.67 \\
\hline${ }^{\star}$ Cancer related to moking $\|(n=122)$ & 1 & $2.40(1.59$ to 3.62$)$ & $4.01(2.44$ to 6.59$)$ & $7.22(1.74$ to 30.08$)$ & $<0.001$ \\
\hline${ }^{\star}$ Cancer unrelated to smoking $(n=185)$ & 1 & $0.95(0.68$ to 1.35$)$ & $1.43(0.91$ to 2.23$)$ & - & 0.40 \\
\hline${ }^{\star}$ Respiratory disease $\dagger \dagger(n=46)$ & 1 & $1.91(1.00$ to 3.63$)$ & $2.02(0.79$ to 5.16$)$ & $9.16(1.20$ to 70.27$)$ & 0.021 \\
\hline${ }^{\star}$ Other $(n=240)$ & 1 & $1.17(0.68$ to 2.01$)$ & $1.35(0.62$ to 2.95$)$ & $3.81(0.52$ to 27.99$)$ & 0.27 \\
\hline & None (4927) & $1-10(1724)$ & $11-20(551)$ & $>20(31)$ & \\
\hline 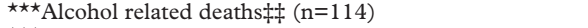 & 1 & $1.31(0.84$ to 2.02$)$ & $1.76(0.97$ to 3.18$)$ & $2.28(0.31$ to 16.77$)$ & 0.045 \\
\hline${ }^{\star \star \star}$ Alcohol related deaths, unrelated to smoking $\mathbb{} \mathbb{}(\mathrm{n}=97)$ & 1 & $1.42(0.90$ to 2.25$)$ & $1.32(0.63$ to 2.74$)$ & $2.67(0.36$ to 19.83$)$ & 0.16 \\
\hline
\end{tabular}

${ }^{\star}$ Adjusted for systolic blood pressure, BMI, father's social class and year of birth quintile. ${ }^{\star \star}$ Additional adjustment for systolic blood pressure. ${ }^{\star \star \star}$ Additional adjustment for alcohol consumption. †International classification of disease, ninth revision (ICD-9) codes 390-459, $\neq$ ICD-9: 410-414, \$ICD-9: 430-438, $₫$ ICD-9: 140141, 143-149, 150, 157, 160-163, 188-189, +†ICD-9: 460-519, łłICD-9: 141, 143-6, 148-9, 150, 155, 161, 291, 303, 571, 800-999, \$§ICD-9: 155, 291, 303, 571, and $800-999$. 
was little effect of controlling for potential confounders only the adjusted hazard ratios are presented (table 1). There were strong positive associations between smoking and death from all causes, CVD, CHD, and smoking related cancer. For respiratory disease and alcohol related disease there was also evidence of a positive association. When smoking related diseases were excluded from the alcohol related disease category the hazard ratio hardly changed although the trend was no longer significant. For stroke, and "other" diseases there was only weak evidence of positive associations.

\section{Discussion}

We show that overall mortality in later life is dramatically increased for men who, in one questionnaire, reported smoking in adolescence and early adult life. The strong positive associations reported here point to specific effects of smoking; no association was seen with diseases unrelated to smoking and the cohort was relatively socoioeconomically homogeneous, so confounding by social circumstances is unlikely to be a serious problem.

Two general explanations are possible. As lifetime smoking habit is usually established at least by early adulthood the findings could point to the importance of the duration of smoking in determining risk. The number of former cigarette smokers aged over 50 in the $\mathrm{UK}$ is double the number of continuing smokers, ${ }^{5}$ and to the extent that some of these affluent students will have quit smoking in later years the findings may underestimate the true size of the effects. Alternatively age at initiation of smoking may be an independent risk factor. It has been shown that current smokers who started smoking when teenagers were at increased risk of total and CVD mortality, ${ }^{3}$ and of lung cancer occurrence, ${ }^{6}$ compared with those who started smoking later in life.

Demonstrating the direct influence of smoking at younger ages on later mortality may be useful in health promotion, as it clearly illustrates the relevance of smoking behaviour in adolescence and early adult life. Young people who smoke may feel that they can give up the habit later in life, ${ }^{7}$ and although many undoubtedly do, our findings demonstrate that individuals who were adults and largely affluent during a period when the hazards of smoking were generally well known still have substantial mortality risks attributable to smoking. In summary the results reinforce the dual need to prevent teenagers starting smoking and to encourage young smokers to quit.

The authors would like to thank Alan Kerr, Christine Hamilton, and Heather Learmonth for help with data entry.

Funding: Chest Heart and Stroke (Scotland), Stroke Association, NHS Management Executive, Cardiovascular Disease and Stroke Research and Development Initiative.

Conflicts of interest: none.

1 Secretary of State for Health and the Secretaries of State for Scotland, Wales and Northern Ireland. Smoking Kills White Paper on Tobacco: London: Stationery Office, 1998.

2 Paffenbarger RS, Wing AL, Hyde RT. Physical activity as an index of heart attack risk in college alumni. Am f Epidemiol 1978;108:161-75.

3 Kawachi I, Colditz GA, Stampfer MJ, et al. Smoking cessation and decreased risk of stroke in women. FAMA 1993;269:232-6.

4 McCarron P, Davey Smith G, Okasha M, et al. Life course exposure and later disease: a follow-up study based on medical examinations carried out in Glasgow University (1948-68). Public Health 1999;113:265-71.

5 Office for National Statistics. Results from the 1998 general household survey. London: Stationery Office, 2000.

6 Hegmann KT, Fraser AM, Keaney RP, et al. The effect of age at smoking initiation on lung cancer risk. Epidemiology 1993;4:444-8.

7 Peto R, Darby S, Deo H, et al. Smoking, smoking cessation, and lung cancer in the UK since 1950: combination of national statistics with two case-control studies. $B M \mathcal{F}$ 2000;321:323-9. 